\title{
Crossover Evaluation of Compressors and Nebulizers Typically Used by Cystic Fibrosis Patients
}

\author{
Samah M Awad MBBS and Ariel Berlinski MD
}

\begin{abstract}
BACKGROUND: Compressor/nebulizer units are used to deliver inhaled medications to patients with cystic fibrosis. Practitioners and parents frequently replace either the compressor or the nebulizer with a similar component from a different brand. We hypothesized that these changes could affect the compressor/nebulizer flow-pressure and aerosol characteristics. METHODS: The following compressors were studied: Pari Vios, Pulmo-Aide model 5650D, and Inspiration Elite model HS456. The following nebulizers were studied: Pari LC Plus, Viox, and SideStream Plus. Units that underwent intense use were tested. The recommended compressor/nebulizer combinations by the manufacturers were compared to all other combinations. In-line measurements of maximal flow and pressure were done for all combinations. A Next Generation Impactor was used to determine particle-size characteristics of albuterol $(2.5 \mathrm{mg} / 3 \mathrm{~mL})$. A breathing simulator programmed to deliver an adult breathing pattern was used. Albuterol concentration was measured with spectrophotometry at $276 \mathrm{~nm}$. The following variables were studied: maximal flow and pressure generated by the compressor/nebulizer, mass median aerodynamic diameter, percentage of drug mass contained in particles $<5 \mu \mathrm{m}$, and inhaled mass in the respirable range. RESULTS: Replacing the nebulizer resulted in changes in the flow-pressure characteristics, particle size, and inhaled mass in the respirable range of the paired compressor/nebulizers. The changes were more pronounced when the nebulizer was replaced than when the compressor was changed. CONCLUSIONS: Our findings indicate that, in general, replacing the nebulizer or compressor with a different brand changes the flow-pressure and aerosol characteristics. Practitioners should be cautious when changing compressor/nebulizer pairs unless they are aware of the resulting impact on the flow-pressure and aerosol characteristics. Key words: nebulizer; compressor; cystic fibrosis; aerosol characteristics; breathing simulation; particle size. [Respir Care 2018;63(3):294-300. () 2018 Daedalus Enterprises]
\end{abstract}

\section{Introduction}

Cystic fibrosis (CF) lung disease is characterized by chronic airway inflammation and infection due to ab-

\footnotetext{
Dr Awad is affiliated with the Department of Pediatrics and Neonatology, Faculty of Medicine, Jordan University of Science and Technology, Irbid, Jordan. Dr Berlinksi is affiliated with the Pediatric Aerosol Research Laboratory, Arkansas Children's Research Institute, and the Pulmonology Section, Department of Pediatrics, College of Medicine, University of Arkansas for Medical Sciences, Little Rock, Arkansas.
}

At the time of this study, Dr Awad was affiliated with the Pulmonology Section, Department of Pediatrics, College of Medicine, University of Arkansas for Medical Sciences.

Dr Awad presented a version of this paper as an abstract at the American Thoracic Society International Meeting, held May 16-21, 2014, in San Diego, California. normal airway secretions and impaired mucociliary clearance. ${ }^{1}$ Progressive lung damage and respiratory failure remain the most serious problems in patients with CF. ${ }^{2}$ Chronic use of medications to maintain lung health improves lung function and slows the progression of the

\footnotetext{
Dr Berlinski discloses relationships with AbbVie, Anthera, Aptalis Pharma, Cempra, Janssen Research and Development, Gilead, National Institutes of Health, Novartis, Therapeutic Development Network, Vertex, and the International Pharmaceutical Aerosol Consortium on Regulation and Science. Dr Awad has disclosed no conflicts of interest. This study was supported in part by the University of Arkansas for Medical Sciences College of Medicine Children's University Medical Group Fund grant program (\#036135). The Pediatric Aerosol Research Laboratory at Arkansas Children's Hospital Research Institute was partially established by and receives partial support from the George Endowment for Asthma.
} 


\section{Compressors and Nebulizers Used by CF Patients}

disease. ${ }^{3,4}$ The United States Cystic Fibrosis Foundation and European Cystic Fibrosis Society recommend the use of the following inhaled medications for pulmonary care: tobramycin, aztreonam, dornase alfa, and hypertonic saline. ${ }^{3-5}$ Although there is insufficient evidence to support chronic use of $\beta_{2}$-adrenergic receptor agonists based on recent $\mathrm{CF}$ guidelines, their limited use can benefit patients with $\mathrm{CF}$ who experience airway hyper-responsiveness. ${ }^{4}$

Nebulizers connected to compressors are used to deliver inhaled medications to patients with CF. The flow and pressure characteristics of the compressor/nebulizer units affect the aerosol properties (eg, particle size generated, nebulization time, and drug output), which are essential determinants of inhaled medication delivery. ${ }^{6-8}$ We have previously reported the effects of 6-month intense use of compressor/nebulizers typically used by patients with $\mathrm{CF} .{ }^{9}$

There are several compressor/nebulizer brands that are advertised to deliver inhaled medications to patients with $\mathrm{CF}$. The package inserts list approved compressor/nebulizer combinations (ie, dornase alfa, tobramycin). ${ }^{10,11} \mathrm{~Pa}$ tients and health care personnel may not follow the recommendations to use certain compressor/nebulizer combinations due to financial or educational considerations. Although previous studies have examined different combinations of compressors/nebulizers, there are limited data on the devices most commonly used by patients with $\mathrm{CF}$ in the United States. ${ }^{7}$

The following situations could occur in clinical practice: the compressor may stop working and be replaced by a compressor of a different brand, or the nebulizer may be replaced by another nebulizer of a brand that is not recommended by the compressor manufacturer. The aim of this study was to determine the flow-pressure and aerosol characteristics of different combinations of compressors and nebulizers that are commonly used in the CF population. These combinations have undergone intense use to simulate real-life experiences by patients with CF. We hypothesized that combining different compressors and nebulizers that are not recommended by manufacturers would affect flow-pressure measurements, particle size distribution, and drug output.

\footnotetext{
Correspondence: Samah M Awad MBBS, Department of Pediatrics and Neonatology, Jordan University of Science and Technology, P.O. Box 3030, Irbid 22110, Jordan, King Abdullah University Hospital. E-mail: smawad@just.edu.jo.
}

DOI: $10.4187 /$ respcare. 05892

\section{QUICK LOOK}

\section{Current knowledge}

Patients with cystic fibrosis use inhaled medications to maintain their lung health. During treatment, it is possible that one of the components of the compressor/nebulizer equipment may be replaced by another device of a different brand. The effect of changing components of devices that are used by patients with cystic fibrosis is poorly understood.

\section{What this paper contributes to our knowledge}

Replacing either the compressor or nebulizer in the compressor/nebulizer equipment resulted in changes in the flow/pressure and aerosol characteristics. Therefore, nebulizers and compressor should not be considered interchangeable.

\section{Methods}

\section{Compressors, Nebulizers, and Study Design}

The following compressors were studied: Pari Vios (Pari Respiratory Equipment, Midlothian, Virginia), Pulmo-Aide model 5650D (DeVilbiss Healthcare, Somerset, Pennsylvania), and Inspiration Elite model HS456 (Philips Respironics, Parsippany, New Jersey). The following nebulizers were studied: Pari LC Plus (Pari Respiratory Equipment), Viox 1 (DeVilbiss Healthcare) and SideStream Plus model HS870 durable nebulizer (Philips Respironics). The following compressor/nebulizer combinations were studied; the number of each combination is shown in parentheses: Pari Vios/Viox (2), Pari Vios/SideStream Plus (2), PulmoAide/Pari LC Plus (4), Pulmo-Aide/SideStream Plus (4), Inspiration Elite/Pari LC Plus (4), and Inspiration Elite/Viox (4).

All devices underwent intense use to simulate use by patients with CF by operating them for $1 \mathrm{~h}$ twice daily for 24 weeks. The characteristics of the recommended pairs of compressor/nebulizer combinations have been previously reported. ${ }^{9}$ Four units were studied from each brand except for the Pari Vios because there were 2 working units from the previous study. The following measurements were recorded using the previously described methodology: flow, pressure, particle size distribution, and breathing simulation. ${ }^{9}$ The study was performed at the Pediatric Aerosol Research Laboratory, Arkansas Children's Research Institute, Little Rock, Arkansas.

\section{Flow and Pressure Measurements}

The connection of the system involved the compressor, pressure meter (SPER Scientific LTD model 840065 Scotts- 


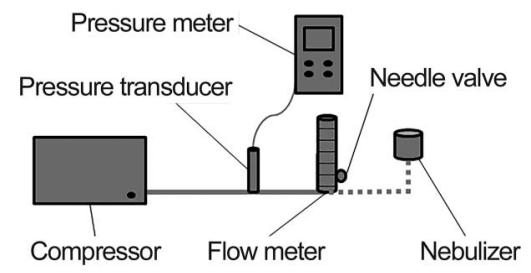

Fig. 1. Experimental setup used to measure flow and pressure. From Reference 9.

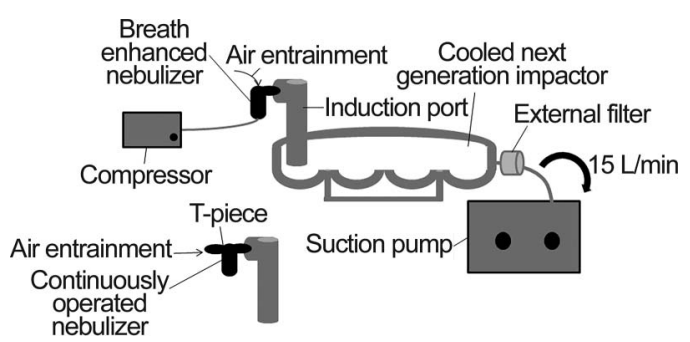

Fig. 2. Experimental setup used to measure particle size. From Reference 9.

dale, Arizona), flow meter (100 mm scale for air, 2-20 L/min; Cole Palmer Instrument, Vernon Hills, Illinois), and nebulizer (without a solution) in sequence with tubing (Fig. 1).9,12 The flow meter had a needle valve that allowed adjustment of the flow. After operating the compressor connected to the nebulizer for 2 min, the maximal flow $(\mathrm{MF} / \mathrm{NEB})$ and the maximal pressure $(\mathrm{P} / \mathrm{NEB})$ were recorded with the needle valve fully opened.

\section{Particle Size Analysis}

The measurement of particle size was performed by cascade impaction, and the data were analyzed according to U.S. Pharmacopeia recommendations. A Next Generation Impactor (NGI 170, MSP Corporation, Shoreview, Minnesota) was used with similar methodology as published in previous studies (Fig. 2).9,13 The NGI was calibrated at $15 \mathrm{~L} / \mathrm{min}$ and then cooled to $4^{\circ} \mathrm{C}$. Each nebulizer tested was loaded with albuterol sulfate $(2.5 \mathrm{mg} / 3 \mathrm{~mL}$, Nephron Pharmaceuticals, Orlando, Florida) before it was connected to the NGI, and it was run for $4 \mathrm{~min}$. After nebulization was complete, we added ultrapure water to the different components of the NGI and nebulizers. The washings were tested for albuterol concentration via spectrophotometry at $276 \mathrm{~nm}$ (BioMate 3 spectrophotometer, Thermo Electron, Waltham, Massachusetts). The mass median aerodynamic diameter (MMAD), geometric standard deviation (GSD), and percentage of drug mass contained in particles $<5 \mu \mathrm{m}(\mathrm{P} \%<5)$ were calculated using CITDAS 3.1 software (Copley Scientific, Nottingham, United Kingdom).

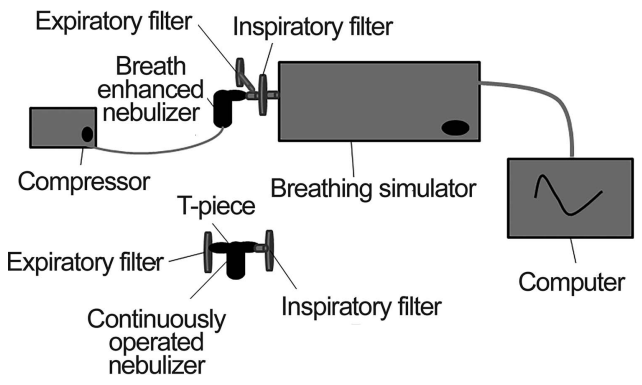

Fig. 3. Experimental setup used for simulated breathing. From Reference 9.

\section{Breathing Simulation}

The inhaled mass in the respirable range (IM-RR) was determined by breathing simulation after nebulizing the albuterol sulfate $(2.5 \mathrm{mg} / 3 \mathrm{~mL})$ for $10 \mathrm{~min}$. The breathing simulator (PARI Compass, Munich, Germany) was calibrated with a mass flow meter (model 4043, TSI, Shoreview, Minnesota). ${ }^{10,14}$ The following breathing pattern, tested previously, was utilized: tidal volume $=500 \mathrm{~mL}$, breathing frequency $=12$ breaths $/ \mathrm{min}$, inspiratory time $=1.7 \mathrm{~s}$, and inspiratory:expiratory ratio $=1: 2 .{ }^{9}$ The nebulizer was connected to the breathing simulator with a low dead-space inspiratory filter (Pari Respiratory Equipment). An external filter was connected to the nebulizer to capture the aerosol wasted during exhalation (Fig. 3). After albuterol nebulization was complete, the concentration of albuterol captured by the inspiratory filter was considered the inhaled mass (IM, $\mu \mathrm{g}$ ) and was measured with spectrophotometry. The IM in the respirable range (IM-RR) was the proportion of the IM that contained particles $<5 \mu \mathrm{m}$ and was calculated as $(\mathrm{IM} \times \mathrm{P} \%<5) / 100$.

\section{Statistical Analysis}

There were 6 variables of interest in this study: MF/NEB, $\mathrm{P} / \mathrm{NEB}, \mathrm{MMAD}, \mathrm{GSD}, \mathrm{P} \%<5$ and IM-RR. Analysis of variance was used to compare measurements between each compressor and the tested nebulizer with the recommended combination; data from Awad et al. ${ }^{9} \mathrm{We}$ conducted a post hoc analysis for multiple comparisons with Dunnet's test. A $t$ test was used to compare groups with unequal size. All $P$ values $<.05$ were considered statistically significant.

\section{Results}

\section{Effect of Changing Nebulizers}

The effects on aerosol characteristics of changing nebulizers while maintaining the same compressor are shown 
Table 1. Effect on Aerosol Characteristics of Changing Nebulizers While Maintaining the Same Compressor

\begin{tabular}{|c|c|c|c|c|}
\hline \multirow{2}{*}{ Compressor } & \multirow{2}{*}{ Variable } & \multicolumn{3}{|c|}{ Nebulizer } \\
\hline & & Pari LC Plus $\dagger$ & Viox & SideStream Plus \\
\hline \multirow[t]{7}{*}{ Pari Vios } & $\mathrm{MF} / \mathrm{NEB}, \mathrm{L} / \mathrm{min}$ & $4.0 \pm 0.5$ & $4.5 \pm 0.5(P=.23)$ & $3.8 \pm 0.3(P=.78)$ \\
\hline & $\mathrm{P} / \mathrm{NEB}, \mathrm{psi}$ & $14.3 \pm 3.9$ & $8.4 \pm 3.3(P<.001)$ & $15.8 \pm 2.8(P=.07)$ \\
\hline & MMAD, $\mu \mathrm{m}$ & $5.17 \pm 0.35$ & $5.41 \pm 0.39(P=.88)$ & $3.74 \pm 0.44(P=.18)$ \\
\hline & GSD & $1.70 \pm 0.07$ & $1.52 \pm 0.11(P=.73)$ & $1.83 \pm 0.37(P=.84)$ \\
\hline & $\mathrm{P} \%<5, \%$ & $48.1 \pm 5.8$ & $43.2 \pm 7.5(P=.73)$ & $67.7 \pm 1.7(P=.15)$ \\
\hline & $\mathrm{IM}-\mathrm{RR}, \mu \mathrm{g}$ & $140.6 \pm 19.4$ & $151.5 \pm 49.3(P=.94)$ & $341.6 \pm 7.9(P=.049)$ \\
\hline & Variable & $\operatorname{Viox} \dagger$ & Pari LC Plus & SideStream Plus \\
\hline \multirow[t]{7}{*}{ Pulmo-Aide } & $\mathrm{MF} / \mathrm{NEB}, \mathrm{L} / \mathrm{min}$ & $6.5 \pm 0.0$ & $4.6 \pm 0.3(P<.001)$ & $4.5 \pm 0.0(P<.001)$ \\
\hline & $\mathrm{P} / \mathrm{NEB}, \mathrm{psi}$ & $12.6 \pm 0.7$ & $19.3 \pm 1.3(P<.001)$ & $19.9 \pm 1.6(P<.001)$ \\
\hline & MMAD, $\mu \mathrm{m}$ & $4.6 \pm 0.3$ & $4.2 \pm 0.3(P=.56)$ & $3.4 \pm 0.1(P<.001)$ \\
\hline & GSD & $1.39 \pm 0.10$ & $2.19 \pm 0.10(P<.001)$ & $2.15 \pm 0.08(P<.001)$ \\
\hline & $\mathrm{P} \%<5, \%$ & $58.4 \pm 6.1$ & $56.7 \pm 3.4(P=.83)$ & $68.5 \pm 1.8(P=.002)$ \\
\hline & $\mathrm{IM}-\mathrm{RR}, \mu \mathrm{g}$ & $209.2 \pm 41.4$ & $215.2 \pm 26.5(P=.87)$ & $267.1 \pm 68(P=.20)$ \\
\hline & Variable & SideStream Plus $\dagger$ & Pari LC Plus & Viox \\
\hline \multirow[t]{6}{*}{ Inspiration Elite } & $\mathrm{MF} / \mathrm{NEB}, \mathrm{L} / \mathrm{min}$ & $5.1 \pm 0.3$ & $5.0 \pm 0(P=.42)$ & $6.1 \pm 0.3(P<.001)$ \\
\hline & $\mathrm{P} / \mathrm{NEB}, \mathrm{psi}$ & $18.9 \pm 0.6$ & $18.1 \pm 0.8(P=.07)$ & $11.8 \pm 0.3(P<.001)$ \\
\hline & MMAD, $\mu \mathrm{m}$ & $3.1 \pm 0.3$ & $4.6 \pm 0.2(P<.001)$ & $4.9 \pm 0.3(P<.001)$ \\
\hline & GSD & $2.19 \pm 0.07$ & $1.47 \pm 0.16(P<.001)$ & $1.46 \pm 0.13(P<.001)$ \\
\hline & $\mathrm{P} \%<5, \%$ & $70.6 \pm 5.2$ & $59.9 \pm 4.8(P=.061)$ & $52.6 \pm 5.6(P=.007)$ \\
\hline & $\mathrm{IM}-\mathrm{RR}, \mu \mathrm{g}$ & $297.5 \pm 130.3$ & $243.4 \pm 55(P=.52)$ & $189.2 \pm 5.1(P=.15)$ \\
\hline $\begin{array}{l}P \text { values show differen } \\
\dagger \text { Nebulizer recommen } \\
\mathrm{MF} / \mathrm{NEB}=\text { maximal } \mathrm{f} \\
\mathrm{P} / \mathrm{NEB}=\text { pressure of } \\
\mathrm{psi}=\text { pounds } / \text { square in } \\
\mathrm{MMAD}=\text { mass media } \\
\mathrm{GSD}=\text { geometric SD } \\
\mathrm{P} \%<5=\text { percentage } \\
\mathrm{IM}-\mathrm{RR}=\text { inhaled mass }\end{array}$ & $\begin{array}{l}\text { ference nebulizer. Data } \\
\text { nufacturer to be used by } \\
\text { olizer } \\
\text { c diameter } \\
\text { contained in particles }<5 \\
\text { ble range }\end{array}$ & $\begin{array}{l}\text { rence } 9 . \\
\text { or. }\end{array}$ & & \\
\hline
\end{tabular}

in Table 1. The Pari Vios compressor was used with the Viox nebulizer instead of the Pari LC Plus. The results were similar except for a lower P/NEB. Replacing the Pari LC Plus with the SideStream Plus nebulizer when using the Pari Vios compressor also yielded similar results except for a 2.4-fold increase in IM-RR.

Combining the Pulmo-Aide compressor with the Pari LC Plus instead of the Viox nebulizer resulted in a lower MF/NEB and higher P/NEB and GSD. However, values for MMAD, $\mathrm{P} \%<5$, and IM-RR were simlar. When the Pulmo-Aide compressor was operated with the SideStream Plus nebulizer instead of the Viox nebulizer, the results were similar for IM-RR, higher for P/NEB, GSD, and $\mathrm{P} \%<5$, and lower for MF/NEB and MMAD.

When the Inspiration Elite compressor was tested with the Pari LC Plus nebulizer instead of the SideStream Plus nebulizer, MMAD was higher, GSD was lower, and other variables were similar. When the Viox nebulizer was used with the Inspiration Elite compressor, P/NEB, GSD, and $\mathrm{P} \%<5$ were lower, while MF/NEB and MMAD were higher (Fig. 4 and Fig. 5).

\section{Effect of Changing Compressors}

The effects on aerosol characteristics of changing nebulizers while maintaining the same compressor are shown in Table 2. When the Pari LC Plus nebulizer was operated with the Pulmo-Aide compressor instead of the Pari Vios compressor, we observed higher values for MF/NEB, $\mathrm{P} / \mathrm{NEB}, \mathrm{GSD}, \mathrm{P} \%<5$, and IM-RR, and a lower value for MMAD. Using the Inspiration Elite compressor with the Pari LC Plus nebulizer resulted in higher values for $\mathrm{MF} / \mathrm{NEB}, \mathrm{P} \%<5$, and IM-RR, and a lower value for MMAD; P/NEB values were similar to the original setup.

Operating the Viox nebulizer with the Pari Vios compressor instead of the Pulmo-Aide compressor resulted in 


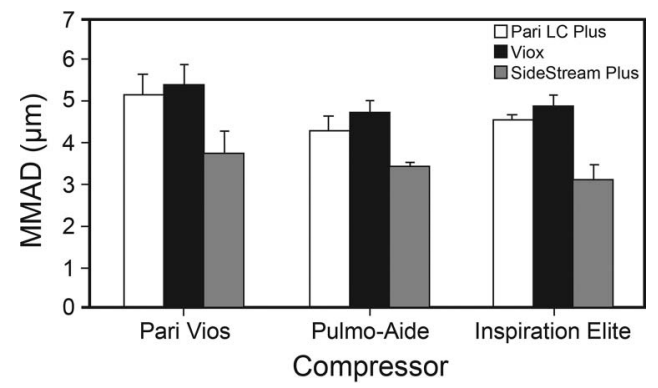

Fig. 4. Mass median aerodynamic diameter (MMAD) of albuterol aerosols generated by different compressor/nebulizer combinations.

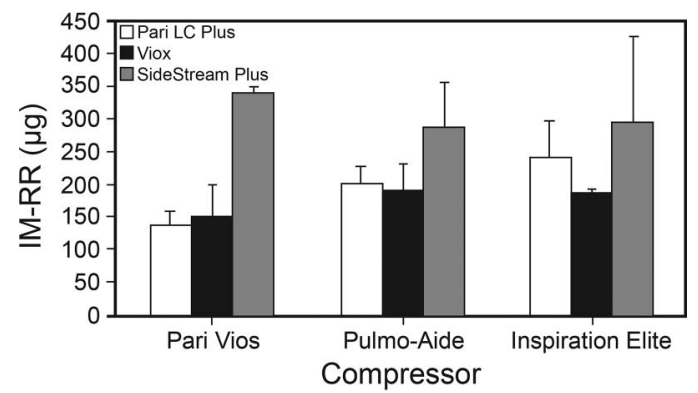

Fig. 5. Inhaled mass in the respirable range (IM-RR) of albuterol aerosols generated by different compressor/nebulizer combinations.

lower values for MF/NEB and P/NEB; the results for the other variables were similar to the original setup. When the Inspiration Elite compressor was combined with the Viox nebulizer, we found that all of the studied variables were similar.

When we paired the SideStream Plus nebulizer with the Pari Vios compressor instead of the Inspiration Elite compressor, and results for MF/NEB and GSD were lower while the other variables had similar values. When we used the Pulmo-Aide compressor with the SideStream Plus nebulizer, the values of MF/NEB were lower while the other variables had similar results.

\section{Discussion}

We studied the effects of replacing either the compressor or nebulizer in compressor/nebulizer combinations on the flow/pressure and aerosol characteristics in breathing simulations intended to mimic use by patients with CF. We found that replacing the nebulizer with one of a different brand affected the aerosol characteristics more than replacing the compressor with one of a different brand.

\section{Effect of Changing the Nebulizer}

The majority of changes in the nebulizer brand resulted in significant changes to the aerosol characteristics. Our results are consistent with previously reported data. ${ }^{7,15}$ Melani ${ }^{15}$ compared the aerosol characteristics of albuterol and several drug admixtures generated by a compressor and 2 different models of nebulizers from the same manufacturer. Melani ${ }^{15}$ reported that changing the nebulizer resulted in albuterol aerosols that had a 30\% higher drug output and lower MMAD. Smith et $\mathrm{al}^{7}$ compared $23 \mathrm{com}-$ pressor/nebulizer combinations and found that there were significant variations in $\mathrm{P} \%<5$ when the nebulizer was combined with each of the 4 different tested compressor brands.

\section{Effect of Changing the Compressor}

We found that replacing the Pulmo-Aide compressor with either the Pari Vios compressor or the Inspiration Elite compressor when using the Viox nebulizer did not affect the aerosol characteristics. Similarly, replacing the Inspiration Elite compressor with either the Pari Vios compressor or the Pulmo-Aide compressor when using the SideStream Plus nebulizer did not affect the aerosol characteristics. Conversely, several changes in aerosol characteristics were observed when the Pari LC Plus nebulizer was operated with a compressor other than the Pari Vios.

Our findings regarding the Pari LC Plus nebulizer are similar to those of other investigators. ${ }^{16-18}$ The study by de Boer et $\mathrm{al}^{16}$ examined the aerosol characteristics of tobramycin using a Pari LC PLUS nebulizer coupled to 5 different compressors. Their study showed up to a 2 -fold variation in the MF/NEB when the compressor was changed, and their reported MF/NEB value for the PulmoAide/Pari LC Plus was similar to our result (4 vs 4.6 $\mathrm{L} / \mathrm{min}$ ). They found that the changes in MMAD were in the range of 1.7 -fold between different compressors, and that the smallest MMAD was generated by the compressor with the lowest MF/NEB. In another study, Berg and Picard ${ }^{17}$ compared the output of budesonide with 30 different compressor/nebulizers. The Pari LC Plus nebulizer was compared with 2 different compressors and resulted in MMAD values of $6.2 \mu \mathrm{m}$ and $7.2 \mu \mathrm{m}$. They also found $\mathrm{P} \%<5$ of $28 \%$ and $35 \%$, respectively. Standaert et al ${ }^{18}$ compared the aerosol characteristics of tobramycin generated by a Pari LC Plus nebulizer with 8 different compressors and reported a difference of up to 1.5-fold in MMAD values among different compressors.

The importance of the in vitro differences reported in several studies correlates with the findings of Westerman et al, ${ }^{19}$ who reported different pharmacokinetic values for inhaled tobramycin when using the Pari LC Plus with either the CR60 or Portaneb. In contrast, Fiel et $\mathrm{a}^{20}$ found no differences in clinical effects when recombinant human DNase I was delivered by 3 different compressor/nebulizer systems. However, the systems used had similar in vitro characteristics. 
Table 2. Effect on Aerosol Characteristics of Changing Compressors While Maintaining the Same Nebulizer

\begin{tabular}{|c|c|c|c|c|}
\hline \multirow{2}{*}{ Nebulizer } & \multirow{2}{*}{ Variable } & \multicolumn{3}{|c|}{ Compressor } \\
\hline & & Pari Vios $\dagger$ & Pulmo-Aide & Inspiration Elite \\
\hline \multirow[t]{7}{*}{ Pari LC Plus } & $\mathrm{MF} / \mathrm{NEB}, \mathrm{L} / \mathrm{min}$ & $4.0 \pm 0.5$ & $4.6 \pm 0.3(P=.003)$ & $5.0 \pm 0(P=.02)$ \\
\hline & $\mathrm{P} / \mathrm{NEB}, \mathrm{psi}$ & $14.3 \pm 3.9$ & $19.3 \pm 1.3(P=.048)$ & $18.1 \pm 0.8(P=.15)$ \\
\hline & MMAD, $\mu \mathrm{m}$ & $5.17 \pm 0.35$ & $4.31 \pm 0.23(P=.030)$ & $4.55 \pm 0.18(P=.02)$ \\
\hline & GSD & $1.70 \pm 0.07$ & $2.19 \pm 0.10(P=.002)$ & $1.47 \pm 0.16(P=.056)$ \\
\hline & $\mathrm{P} \%<5, \%$ & $48.1 \pm 5.8$ & $56.7 \pm 3.4(P=.030)$ & $59.9 \pm 4.8(P=.008)$ \\
\hline & $\mathrm{IM}-\mathrm{RR}, \mu \mathrm{g}$ & $140.6 \pm 19.4$ & $215.2 \pm 26.5(P=.030)$ & $243.4 \pm 55(P=.009)$ \\
\hline & Variable & Pulmo-Aide $\dagger$ & Pari Vios & Inspiration Elite \\
\hline \multirow[t]{7}{*}{ Viox } & $\mathrm{MF} / \mathrm{NEB}, \mathrm{L} / \mathrm{min}$ & $6.5 \pm 0.0$ & $4.5 \pm 0.5(P<.001)$ & $6.1 \pm 0.3(P=.32)$ \\
\hline & $\mathrm{P} / \mathrm{NEB}, \mathrm{psi}$ & $12.6 \pm 0.7$ & $8.4 \pm 3.3(P=.040)$ & $11.8 \pm 0.3(P=.99)$ \\
\hline & $\mathrm{MMAD}, \mu \mathrm{m}$ & $4.6 \pm 0.3$ & $5.4 \pm 0.5(P=.056)$ & $4.9 \pm 0.3(P=.65)$ \\
\hline & GSD & $1.39 \pm 0.10$ & $1.52 \pm 0.11(P=.23)$ & $1.46 \pm 0.13(P=.58)$ \\
\hline & $\mathrm{P} \%<5, \%$ & $58.4 \pm 6.1$ & $43.2 \pm 7.5(P=.07)$ & $52.6 \pm 5.6(P=.67)$ \\
\hline & $\mathrm{IM}-\mathrm{RR}, \mu \mathrm{g}$ & $209.2 \pm 41.4$ & $151.5 \pm 49.3(P=.25)$ & $189.2 \pm 5.1(P=.99)$ \\
\hline & Variable & Inspiration Elite $\dagger$ & Pari Vios & Pulmo-Aide \\
\hline \multirow[t]{6}{*}{ SideStream Plus } & $\mathrm{MF} / \mathrm{NEB}, \mathrm{L} / \mathrm{min}$ & $5.1 \pm 0.3$ & $3.8 \pm 0.3(P<.001)$ & $4.5 \pm 0.0(P=.009)$ \\
\hline & $\mathrm{P} / \mathrm{NEB}$, psi & $18.9 \pm 0.6$ & $15.8 \pm 2.8(P=.15)$ & $19.9 \pm 1.6(P=.99)$ \\
\hline & MMAD, $\mu \mathrm{m}$ & $3.1 \pm 0.3$ & $3.8 \pm 0.5(P=.15)$ & $3.4 \pm 0.1(P=.61)$ \\
\hline & GSD & $2.19 \pm 0.07$ & $1.83 \pm 0.37(P=.040)$ & $2.15 \pm 0.08(P=.90)$ \\
\hline & $\mathrm{P} \%<5, \%$ & $70.6 \pm 5.2$ & $67.7 \pm 1.7(P=.99)$ & $68.5 \pm 1.8(P=.99)$ \\
\hline & $\mathrm{IM}-\mathrm{RR}, \mu \mathrm{g}$ & $297.5 \pm 130.3$ & $341.6 \pm 7.9(P=.99)$ & $267.1 \pm 68(P=.99)$ \\
\hline $\begin{array}{l}P \text { values show differen } \\
\dagger \text { Compressor recomm } \\
\text { MF/NEB = maximal } \mathrm{f} \\
\mathrm{P} / \mathrm{NEB}=\text { pressure of } \\
\mathrm{psi}=\text { pounds } / \text { square in } \\
\mathrm{MMAD}=\text { mass media } \\
\mathrm{GSD}=\text { geometric SD } \\
\mathrm{P} \%<5=\text { percentage } \\
\mathrm{IM}-\mathrm{RR}=\text { inhaled mas }\end{array}$ & $\begin{array}{l}\text { ference nebulizer. Data } \\
\text { nanufacturer to be used } \\
\text { olizer } \\
\text { c diameter } \\
\text { contained in particles }<5 \\
\text { ble range }\end{array}$ & $\begin{array}{l}\text { rence } 9 . \\
\text { izer. }\end{array}$ & & \\
\hline
\end{tabular}

In contrast to the results found for the Pari LC Plus, changing the compressor to either the Pari Vios or SideStream Plus nebulizer did not change the aerosol characteristics. These findings are in agreement with previously reported data. Smith et $\mathrm{al}^{7}$ compared 23 compressor/nebulizer combinations and found no changes in $\mathrm{P} \%<5$ for one nebulizer if the different compressors generated similar pressures and flows.

The clinical implications of this study are that patients, caregivers, and health care providers must be aware of the effects of substituting either a compressor or a nebulizer on the aerosol characteristics of a nebulized drug. Additional studies are needed to include more compressor and nebulizer models and test different drugs that are nebulized for patients with CF. A limitation of our study that is that we studied only albuterol and no other nebulized drugs (eg, dornase alfa, tobramycin).

\section{Conclusions}

Changes in the aerosol characteristics of a nebulized drug often occur when either the compressor or nebulizer are replaced by a component of a different brand. This effect is more pronounced for nebulizer substitution. The compressor/nebulizer combination should not be interchanged without knowing the characteristics of the resulting aerosols.

\section{REFERENCES}

1. O'Sullivan BP, Freedman SD. Cystic fibrosis. Lancet 2009; 373(9678):1891-1904.

2. Kerem E. Cystic fibrosis: priorities and progress for future therapies. Paediatr Respir Rev 2017;24:14-16.

3. Flume PA, O'Sullivan BP, Robinson KA, Goss CH, Mogayzel PJ, Willey-Courand DB, et al. Cystic fibrosis pulmonary guidelines: 


\section{Compressors and Nebulizers Used by CF Patients}

chronic medications for maintenance of lung health. Am J Respir Crit Care Med 2007;176(10):957-969.

4. Mogayzel PJ, Naureckas ET, Robinson KA, Mueller G, Hadjiliadis D, Hoag JB, et al. Cystic fibrosis pulmonary guidelines. Chronic medications for maintenance of lung health. Am J Respir Crit Care Med 2013;187(7):680-689.

5. Smyth AR, Bell SC, Bojcin S, Bryon M, Duff A, Flume P, et al. European Cystic Fibrosis Society standards of care: best practice guidelines. J Cyst Fibros 2014;13(Suppl 1):S23-S42.

6. Bauer A, McGlynn P, Bovet LL, Mims PL, Curry LA, Hanrahan JP. Output and aerosol properties of 5 nebulizer/compressor systems with arformoterol inhalation solution. Respir Care 2009;54(10):1342-1347.

7. Smith EC, Denyer J, Kendrick AH. Comparison of twenty-three nebulizer/compressor combinations for domiciliary use. Eur Respir J 1995;8(7):1214-1221.

8. Reisner C, Katial RK, Bartelson BB, Buchmeir A, Rosenwasser LJ, Nelson HS. Characterization of aerosol output from various nebulizer/compressor combinations. Ann Allergy Asthma Immunol 2001; 86(5):566-574.

9. Awad S, Williams DK, Berlinski A. Longitudinal evaluation of compressor/nebulizer performance. Respir Care 2014;59(7):1053-1061.

10. TOBI [package insert]. East Hanover, NJ: Novartis Pharmaceuticals Corporation 2009.

11. Pulmozyme [package insert]. South San Francisco, CA: Genetech, Inc. 2014

12. Standaert TA, Bohn SE, Aitken ML, Ramsey B. The equivalence of compressor pressure-flow relationships with respect to jet nebulizer aerosolization characteristics. J Aerosol Med 2001;14(1):31-42.
13. Berlinski A, Hayden JB. Optimization of a procedure used to measure aerosol characteristics of nebulized solutions using a cooled next generation impactor. J Aerosol Med Pulm Drug Deliv 2010; 23(6):397-404.

14. Chavez A, McCracken A, Berlinski A. Effect of face mask dead volume, respiratory rate, and tidal volume on inhaled albuterol delivery. Pediatr Pulmonol 2010;45(3):224-229.

15. Melani AS. Effects on aerosol performance of mixing of either budesonide or beclomethasone dipropionate with albuterol and ipratropium bromide. Respir Care 2011;56(3):319-326.

16. de Boer AH, Hagedoorn P, Frijlink HW. The choice of a compressor for the aerosolisation of tobramycin (TOBI) with the Pari LC PLUS reusable nebuliser. Int J Pharm 2003;268(1-2):59-69.

17. Berg EB, Picard RJ. In vitro delivery of budesonide from 30 jet nebulizer/compressor combinations using infant and child breathing patterns. Respir Care 2009;54(12):1671-1678.

18. Standaert TA, Vandevanter D, Ramsey BW, Vasiljev M, Nardella P, Gmur D, et al. The choice of compressor effects the aerosol parameters and the delivery of tobramycin from a single model nebulizer. J Aerosol Med 2000;13(2):147-153.

19. Westerman EM, Boer AH, Touw DJ, Brun PP, Roldaan AC, Frijlink HW, Heijerman HG. Aerosolization of tobramycin (TOBI) with the Pari LC PLUS reusable nebulizer: which compressor to use? Comparison of the CR60 to the PortaNeb compressor. J Aerosol Med Pulm Drug Deliv 2008;21(3):269-280.

20. Fiel SB, Fuchs HJ, Johnson C, Gonda I, Clark AB. Comparison of three jet nebulizer aerosol delivery systems used to administer recombinant human DNase I to patients with cystic fibrosis. Chest 1995;108(1):153-156. 